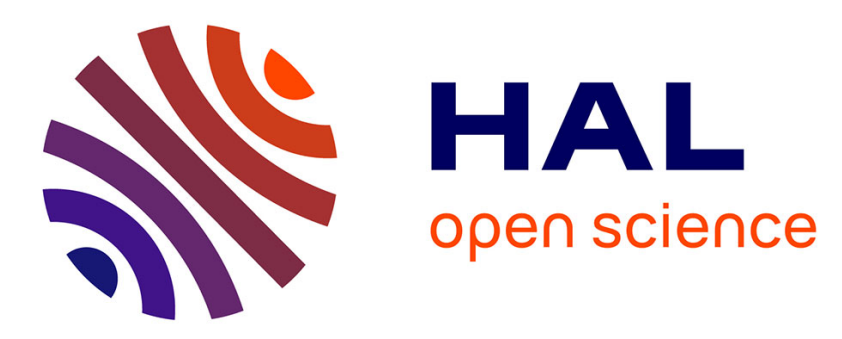

\title{
Unusual PSCs observed by LIDAR in Antarctica
}

Leopoldo Stefanutti, Marco Morandi, Massimo Del Guasta, Sophie Godin, Christine David

\section{To cite this version:}

Leopoldo Stefanutti, Marco Morandi, Massimo Del Guasta, Sophie Godin, Christine David. Unusual PSCs observed by LIDAR in Antarctica. Geophysical Research Letters, 1995, 22 (17), pp.2377-2380. 10.1029/95GL02085 . hal-03038833

\section{HAL Id: hal-03038833 https://hal.science/hal-03038833}

Submitted on 5 Feb 2021

HAL is a multi-disciplinary open access archive for the deposit and dissemination of scientific research documents, whether they are published or not. The documents may come from teaching and research institutions in France or abroad, or from public or private research centers.
L'archive ouverte pluridisciplinaire HAL, est destinée au dépôt et à la diffusion de documents scientifiques de niveau recherche, publiés ou non, émanant des établissements d'enseignement et de recherche français ou étrangers, des laboratoires publics ou privés. 


\title{
Unusual PSCs observed by LIDAR in Antarctica
}

\author{
Leopoldo Stefanutti', Marco Morandi', Massimo Del Guasta', Sophie Godin², \\ and Cristine David ${ }^{2}$
}

\begin{abstract}
Polar Stratospheric Cloud (PSC) measurements by ground-based LIDAR were carried out at Dumont d'Urville, Antarctica, during the years 1989 to 1993. From such measurements it can be seen that there are cases of PSCs that are not consistent with the simplest nitric acid trihydrate (NAT) theories. Several cases of long-lasting, non-depolarizing PSCs were detected at temperatures below or close to the NAT freezing threshold, at about $195^{\circ} \mathrm{K}$, suggesting the presence of durable supercooled droplets. PSC cases showing depolarizing (frozen) particles well above the NAT expected threshold are also shown. These results seems to be more consistent with recent laboratory and in situ findings, suggesting a close link between sulfate and PSC particles through the $\mathrm{HNO}_{3}-\mathrm{H}_{2} \mathrm{O}-\mathrm{H}_{2} \mathrm{SO}_{4}$ ternary system. In this framework, non-depolarizing clouds observed below and close to $195^{\circ} \mathrm{K}$ would arise from the uptake of $\mathrm{HNO}_{3}$ and water by the background particles before the freezing of the ternary system and the successive growth in nitric-acid hydrates. Depolarizing "warm" PSCs are also consistent with the laboratory-observed high melting point of the frozen sulfate core, that remains after NAT evaporation. A problematic PSC case, that cannot be easily explained by this theory is also shown.
\end{abstract}

\section{Introduction}

Since January 1989, regular LIDAR measurements have been carried out at Dumont d'Urville $\left(66^{\circ} 40^{\prime} \mathrm{S}, 140^{\circ} 01^{\prime} \mathrm{E}\right)$ within the frame of the Polar Ozone LIDAR Experiment (POLE), a cooperative project between the Italian National Program for Antarctic Research (PNRA) and the French Polar Institute. In the years 1989 and 1990, a single wavelength depolarization LIDAR operated for the duration of the entire year [Sacco et al., 1989, Stefanutti et al., 1991]. In January 1991 this system was replaced by a multispectral LIDAR [Stefanutti et al., 1992, Godin at al., 1992].

In [Stefanutti et al., 1991], a first classification of Polar Stratospheric Clouds (PSCs), derived from [Browell et al., 1990], had been adopted for the analysis of PSCs detected during 1989. These PSCs were subdivided into two main classes: those that showed a relatively low scattering ratio $R$, and depolarization ratio $\delta$ larger than $10 \%$ (PSC Ia), and those with relatively high $\mathrm{R}$ and $\delta$ smaller than $10 \%$ (PSC Ib).

$R$ is defined as the ratio $\left(\beta_{A}+\beta_{M}\right) / \beta_{M}$, were $\beta_{A}$ and $\beta_{M}$ are, respectively, the aerosol and molecular backscatter coefficients.

1 Istituto di Ricerca sulle Onde Elettromagnetiche "Nello Carrara" - CNR, Firenze (Italy)

2 Service d'Aeronomie - CNRS, Paris (France)

Copyright 1995 by the American Geophysical Union.

Paper number 95GL02085

0094-8534/95/95GL-02085\$03.00
The definition of $\delta$ is given in the next paragraph. The NAT threshold of about $195^{\circ} \mathrm{K}$ was used to discriminate between PSCs and sulfate peaks in cases of high volcanic loading. In a further and more detailed analysis of the experimental results collected over a five-years period, the occurrence of cases which did not fit into this simple classification has been pointed out. Frozen layers have been detected that are well above the NAT freezing point, and long-lasting supercooled layers have been observed below the NAT freezing point. In the previous years, such PSCs were considered by most of the scientific community to be non-equilibrium NAT clouds, subject to temperature changes that were so fast that laboratory NAT data were no longer applicable. Following the most recent laboratory and field experiments, there has been increasing interest in the $\mathrm{HNO}_{3}-\mathrm{H}_{2} \mathrm{O}-\mathrm{H}_{2} \mathrm{SO}_{4}$ ternary system as a link between background sulfate aerosols and PSCs. Several studies [Zhang et al., 1993a; Molina et al., 1993; Carslaw et al., 1994; Tolbert, 1994] have shown that, in the laboratory, stratospheric sulfate particles can take up a large amount of $\mathrm{HNO}_{3}$ and water as the temperature decreases, leading to significant particle growth before the expected NAT threshold is reached. Subsequent freezing of the $\mathrm{H}_{2} \mathrm{SO}_{4}-\mathrm{HNO}_{3}-\mathrm{H}_{2} \mathrm{O}$ ternary compound (followed by NAT coating) may occur after further cooling at below the NAT freezing point. There are some in-situ indications that $\mathrm{HNO}_{3}$ uptake is at work in PSCs [Drdla et al., 1994].

This hypothesis may explain the LIDAR observation of non-depolarizing (presumably liquid) PSCs both above and below $195^{\circ} \mathrm{K}$. Above $195^{\circ} \mathrm{K}$, such PSCs could be due to $\mathrm{H}_{2} \mathrm{O}$ and $\mathrm{HNO}_{3}$ uptake by pre-existing sulfate particles. Below $195^{\circ} \mathrm{K}$, such PSCs could be due to supercooling of the ternary system.

The melting behavior of PSCs has also been reviewed by new laboratory studies. Also, if NAT evaporates at low temperatures, the sulfuric solid core of the particle is expected to survive well above $195^{\circ} \mathrm{K}$ [Zhang et al., 1993b; Middlebroook et al., 1993]. This is consistent with LIDAR observations of frozen particles above $195^{\circ} \mathrm{K}$. A problem may arise when both warm frozen layers and cold liquid layers are present within a few kilometers of each other, as in the case of July 2, 1993, that will be discussed later. In such case a similar thermal history could be hypothesized for the two layers.. These cases are difficult to explain because, in this theory, the warm frozen particles are supposed to be present in evaporating clouds, and the cold liquid particles, in forming clouds.

\section{Depolarization as a Mean for Distinguishing Liquid and Frozen Particles.}

Depolarization is one of the most important parameters in the interpretation of LIDAR data. The definition of depolarization used here is the ratio of the depolarized signal versus the total signal:

$$
\delta(z)=\frac{P s(z)}{P p(z)+P s(z)}
$$

where $P p$ and $P s$ are the two crossed-polarization components of the LIDAR signals. This way, $\delta(z)$, includes also the molecular 
Dumont dUrille July 8, 1990

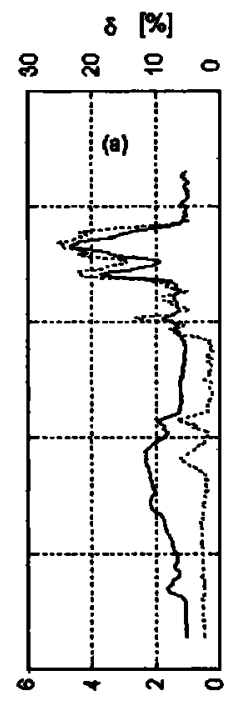

Scatt. Ratio at $532 \mathrm{~nm}$

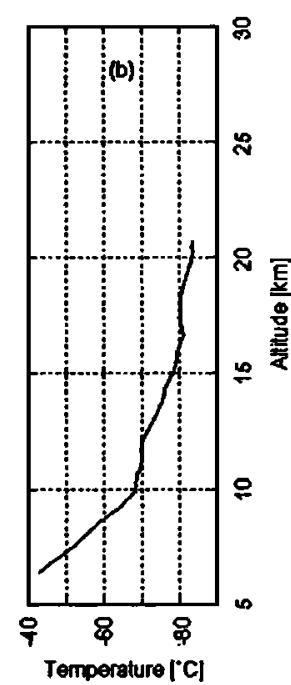
Figure 1. (a) Scattering Ratio (continuous line) and
Depolarization Ratio d (dotted line); (b) Temperature. Volcanic cloud and PSCs. The figure shows the Pinatubo volcanic cloud from about 8 up to $17 \mathrm{~km}$, two depolarizing layers inside the volcanic aerosol (at about $15 \mathrm{~km}$, with a correspondingly low increase in backscattering), and a PSC from 19 up to $24 \mathrm{~km}$.

scattering. LIDAR calibrations carried out in clear-sky conditions provide values for the background depolarization of the order of $2-2.5 \%$, which are consistent with values expected for molecular scattering. Model calculations [Mishchenko M.I. et al., 1994; Flesia et al., 1994], indicate that not only big solid aerosols ( $>1$ micron), but also particles smaller than 1 micron, if non spherical, introduce a non-negligible depolarization. Thus the presence of depolarization is considered a safe sign of the presence of non-spherical aerosols, while the absence of depolarization is assumed to be a sign of the presence of liquid particles. In fact, other than spherical particles, only large $(>\mathbf{2 0 0}$ micron) oriented plates could give no depolarization. However the low water-vapor pressure in the stratosphere strongly reduces the thermodynamical probability of the plate occurrence.

\section{Experimental Results.}

PSC events are regularly detectable over Dumont dUrville from late June to the end of August. Sporadic episodes may occur in early June and September. Stratospheric cooling begins in the second part of June and cold temperatures persist until the warming in early September. Very low tropopause temperatures (down to $193^{\circ} \mathrm{K}$ ) occur regularly, especially in August.

PSC formation always starts from the middle stratosphere in late June-early July, in the region of between $20-25 \mathrm{Km}$, which is the first region to cool down. In August PSCs develop both in the lowest stratosphere and in the 17-25 km region.

Different types of PSCs were observed. PSCs with scattering ratios ranging from 1.5 to above 5 and depolarization peaks up to about $15 \%$ were measured . Most of the cases showed depolarization between 5 and $8 \%$. According to Browell's classification, PSCs with either relatively high or moderate depolarization may be classified as Type Ia or Ib.

Several cases of totally non-depolarizing type-I PSCs were also measured, with LIDAR profiles that showed an absolutely flat depolarization ratio profile.
Case of July 8, 1990. The presence of a well-developed PSC of between 19 and $25 \mathrm{~km}$ (figure 1) was evidenced by the high depolarization, which is similar to that of cirrus clouds. Two depolarization peaks around $15 \mathrm{~km}$ revealed the presence of layers of depolarizing particles, that were well-separated from the higher PSC and not evidenced by a major increase in the scattering ratio. This means that the particles were nonspherical but not much larger than the background particles. The temperature was $193 / 203^{\circ} \mathrm{K}$, higher than but close to the NAT freezing point. Several cases of this kind were collected after the Pinatubo eruption in DDU, but this case was observed earlier. The layers might be composed of evaporating PSC with sulfate cores that had not yet melted.

Nevertheless, this hypothesis cannot be proved from these LIDAR data only, as we could just as likely hypothesize that the layers were just forming!

Case of September 9, 1992. This is another interesting case in which, in spite of the high temperature (15 degrees higher than the suggested PSC I threshold), depolarization peaks showed the presence of layers that were clearly different from Pinatubo aerosol (Figure 2).

Also in this case, the backscattering was not strongly enhanced, showing that the particles were not much larger than those of the background layer. Since this measurement was carried out over the period of one year later than the Mt. Pinatubo eruption, it is scarcely credible that large silicate particles could still be layered in the stratospheric aerosol. Similar cases were frequently observed in September 1992, always with too high temperatures and generally lasting only a few hours. However, this phenomena could be due to PSCs formed in colder region and evaporating over Dumont dUrville, according to the most recent theory, but might also be due to nucleating PSCs.

Case of July 2, 1993. Two sharp depolarization peaks were visible around $19 \mathrm{~km}$ (figure 3), still showing a low scattering

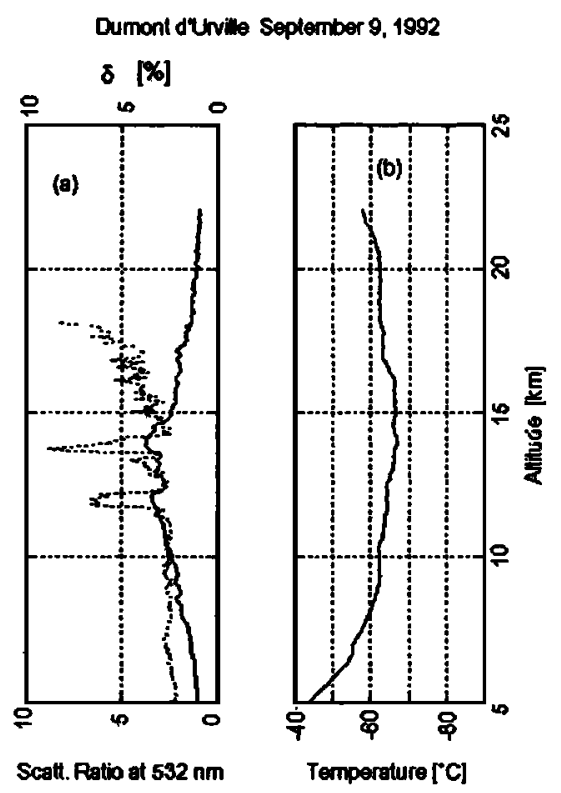

Figure 2. (a) Scattering Ratio (continuous line) and Depolarization Ratio d (dotted line); (b) Temperature. In spite of the rather high temperature, two sharp peaks in the depolarization ratio indicate the presence of depolarizing particles at the center of the Mt. Pinatubo layer. This event occurred several times in September 1992, and all radiosonde data for that month indicated high stratospheric temperatures. 
Dumont ounvilo July 2. 1998

$\delta[\%]$

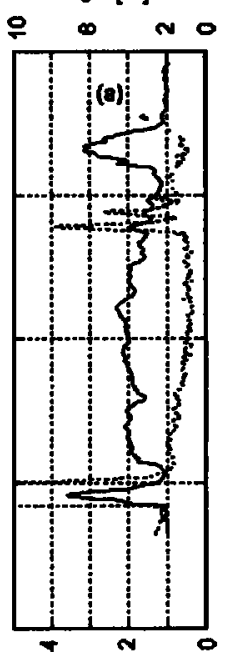

Scatt. Ratio at $532 \mathrm{~nm}$

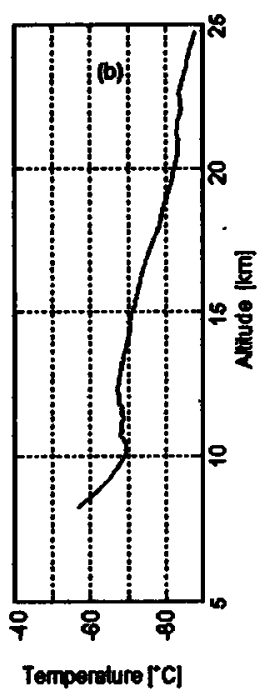

Tempereture $[\mathrm{C}$

Figure 3. (a) Scattering Ratio (continuous line) and Depolarization Ratio d (dotted line); (b) Temperature. Two interesting layers can be observed within the Mt. Pinatubo layer. one is not discernible from the scattering ratio at $18-19 \mathrm{~km}$, a region in which strong depolarization occurs; the other, a cold layer above $20 \mathrm{Km}$, has a scattering ratio of 3 and negligible depolarization ratio. The temperature for the second layer is about $191^{\circ} \mathrm{K}$.

enhancement as in the previous examples. The temperature was about $193^{\circ} \mathrm{K}$, close to the NAT threshold. Discussion regarding these peaks is the same as for the previous cases. A third peak was visible at about $21 \mathrm{~km}$, with a temperature lower than the NAT freezing point.

The prominent peak in the scattering ratio at $21 \mathrm{Km}$ is seen to be non-depolarizing, indicating the presence of liquid particles. This peak could be explained with the $\mathrm{HNO}_{3}$ and water uptake by the background aerosols, an uptake which led to an increased size and backscattering from the liquid particles.

The main problem with this cloud was that the three peaks occurred at the same time. The existence of a supercooled PSC above a warmer layer containing crystalline (depolarizing)

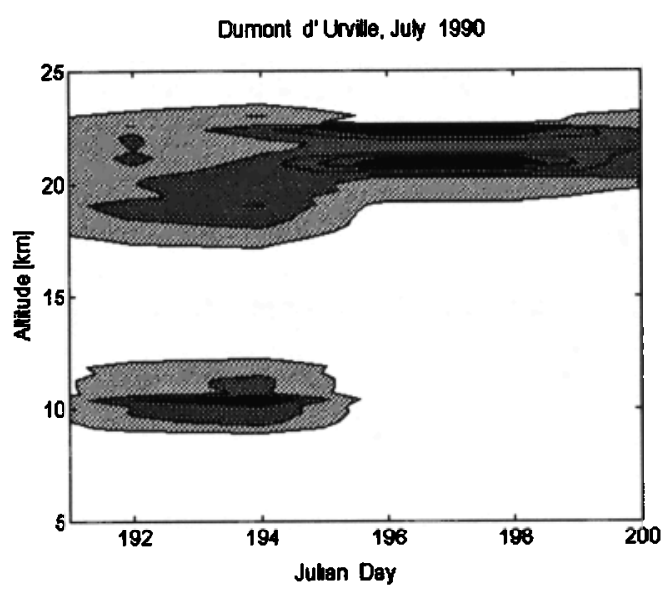

Figure 4. The Scattering Ratio (arbitrary gray scale) is plotted as a function of the altitude and of the Julian day (July 11- July 20, 1990).

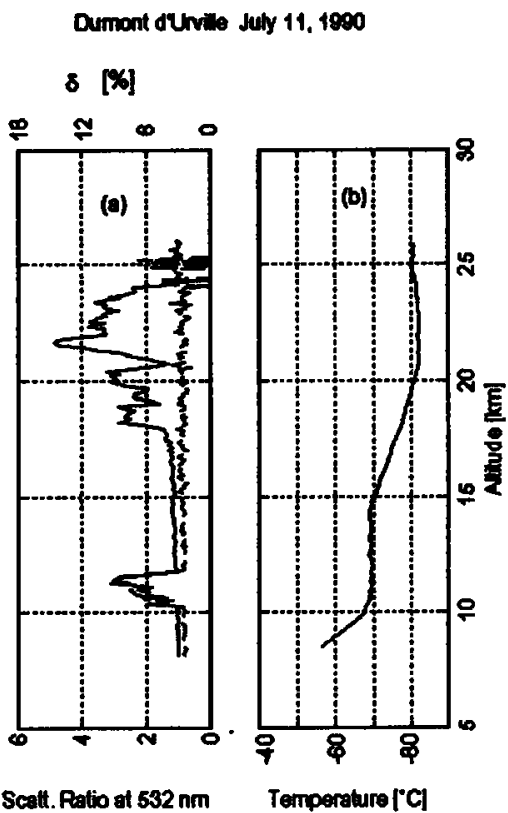

Figure 5. A sample from the event reported in figure 4 (a) Scattering Ratio (continuous line) and Depolarization Ratio d (dotted line); (b) Temperature. A thin cirrus is present at the tropopause; PSCs extend from 17 to $24 \mathrm{~km}$. This enhanced aerosol layer, extending between altitudes with relatively different temperatures, shows quite a strong scattering ratio and absolutely no change in the depolarization ratio compared to the value measured outside the cloud.

particles would seem to be contradictory, unless very different thermal histories characterized the airmasses at 19 and $21 \mathrm{~km}$. Precise trajectories for 19 and $21 \mathrm{~km}$ final heights were not available from Antarctica, and this fact thus shows up the limits of LIDAR data alone in confirming any microphysical theory. Similar cases of very different PSC layers occurring within a few kilometers are to be studied in future years in the Arctic (where modeling of trajectories is less uncertain ), in order to help the PSC theory to develop.

Case of July 11-20, 1990 . Several other cases of non-depolarizing PSCs were observed over Dumont dUrville, particularly in 1990. Some of these PSC events lasted several days. A particularly interesting case started on July 11, 1990 and lasted about 10 days (figure 4).

This PSC event showed, for the whole period, a depolarization that was not distinguishable from the background value, a fact that definitely indicated liquid particles. The stratosphere was cold at the beginning of the event, July 11, and was still cold on July 20 , with temperatures lower than $193^{\circ} \mathrm{K}$ from about $18 \mathrm{~km}$ up. In most of the intermediate days, Rawinsonde balloons exploded at around $15 \mathrm{~km}$, at temperatures close to $193^{\circ} \mathrm{K}$.

Figure 5 shows a sample of this cloud. A high cirrus can be seen just below the cold tropopause, with a scattering ratio of 3 and a depolarization of 7.5\%. The thick PSC starts at about 17 $\mathrm{km}$ and ranges up to $25 \mathrm{Km}$, with a scattering ratio of 3 in the layers between 17 and $21 \mathrm{~km}$ and up to 5 for the layers above.

The depolarization ratio pattern is absolutely flat inside and outside the cloud. This enhanced aerosol layer, that we can call PSC, could be explained with the growth of pre-existing sulfate aerosols by the uptake of water and other gases $\left(\mathrm{HNO}_{3}\right)$ under supercooling conditions. Apparently, the temperature was not cold enough to freeze the particles. The persistence of the liquid 
cloud means that supercooling was preserved on the time scale of a few days.

\section{Discussion and Conclusions}

Previous investigators [e.g. Mishchenko et al., 1994; Flesia et al., 1994] have shown that a small deviation from sphericity in particles bigger than about 0.1 micron can produce a non-negligible depolarization. Such depolarization should be measurable in the presence of small non-spherical particles. The possibility of distinguishing between solid and liquid particles in the stratosphere, also in case of strong volcanic loading, is a powerful tool in lidar science. Using this technique some unusual PSCs were identified above Dumont dUrville. These observations can be explained by the most recent PSC theories involving a $\mathrm{H}_{2} \mathrm{O}-\mathrm{HNO}_{3}-\mathrm{H}_{2} \mathrm{SO}_{4}$ ternary system. Warm ( $>195^{\circ} \mathrm{K}$ ) depolarizing PSCs are thought to be composed of the sulfate cores of evaporated NAT PSCs, that have not yet melted, while non-depolarizing cold clouds are thought to be supercooled solutions of sulfuric and nitric acid. It is still difficult to explain the contemporary presence of both cloud types within a few kilometers of height, due to the lack of back trajectories. LIDAR can only observe the physical phase of the particles and the changes in their size, and that is not enough to confirm a microphysical theory. Any PSC theory that allows the presence of small frozen particles up to $208^{\circ} \mathrm{K}$, supercooled aerosols down to $188^{\circ} \mathrm{K}$, and supercooled aerosols stable for $5-10$ days at $191^{\circ} \mathrm{K}$ is compatible with the data presented in this work.

Acknowledgments. This work was carried out within the frame of the following projects and contributions. Italian Program for Antarctic Research, Institut Polaire Francais, CEC contract EV5V CT92 0066. The authors thanks all the wintering teams that operated the LIDAR at Dumont d'Urville.

\section{References}

Browell, E.V., C.F. Butler, S. Ismail, P.A. Robimette, A.F. Carter, N.S. Hidgon, O.B. Toon, M.R. Shoeberl, A.F. Tuck, Airborne lidar observation in the wintertime Arctic stratosphere, Geophys. Res. Lett., 17, 4, 385, 1990

Carslaw K.S., B.P.Luo, S.L.Clegg,Th.Peter, P.Brimblecombe, and P.J.Crutzen, Stratospheric aerosol growth and $\mathrm{HNO}_{3}$ gas phase depletion from coupled $\mathrm{HNO}_{3}$ and water uptake by liquid particles. Geophys.Res.Lett., .21, 23, 2479-2482, Nov 15,1994 .

Drdla K., A.Tabazadeh, R.P.Turco, and M.J. Jacobson, Analysis of the physical state of one Arctic polar stratospheric cloud based on observations, Geophys. Res. Lett. , 2I, 23, 2475-2478, 1994

Flesia, C., A. Mugnai, Y. Emery, S. Godin, L. de Schoulepnikoff, V. Mitev, Interpretation of lidar depolarization measurements of the Pinatubo stratospheric aerosol layer during EASOE, Geophys. Res. Lett., 21 , 13, 1443-1446, 1994
Godin, S., A. Sarkissian, C. David, G. Megie, J.P. Pommareau, F. Goutail , P. Amedieu, J. Piquard, E. Le Bouar, L Stefanutti, M. Morandi, M. Del Guasta, Systematic stratospheric observations on the Antarctic continent at Dumont d'Urville, NASA Confer. Pubbl., 3266, 561-564, 1992

Middlebrook A.M., L.T.Iraci, L.S. McNeill, B.G.Koehler, M.A.Wilson, O.W.Saastad, and M.A. Tolbert, Fourier transform-infrared studies of thin $\mathrm{H}_{2} \mathrm{SO}_{4}-\mathrm{H}_{2} \mathrm{O}$ films: formation, water uptake, and solid-liquid phase changes. $J$. Geophys. Res., 98, D11, 20473-20481, 1993.

Mishchenko M.I., L.D. Travis, Light scattering by polydispersions of randomly oriented spheroids with sizes comparable to wavelengths of observation, Applied Optics, 33, 30, 1994.

Molina M.J., R.Zhang, P.J. Woolridge, J.R.McMahon, J.E.Kim, H.Y.Chang, K.D. Beyer, Physical chemistry of the $\mathrm{H}_{2} \mathrm{SO}_{4} / \mathrm{HNO}_{3} / \mathrm{H}_{2} \mathrm{O}$ system: implications for polar stratospheric clouds, Science, 261, Sep.1993, 1418-1423.

Sacco, V.M., F. Castagnoli, M. Morandi, and L. Stefanutti, Elastic backscattering lidar system for stratospheric measurements in Antarctica, Opt. and Quantum Electr., 21, 215,1989

Stefanutti, L., M. Morandi., M. Del Guasta, S. Godin., G. Megie, J. Brechet, J. Piquard, Polar stratospheric cloud observations over the Antarctic continent at Dumont d' Urville, J. Geophys . Res., 96, D7, 12975-12987, 1991

Stefanutti, L., F. Castagnoli, M. Del Guasta, M. Morandi, V. M. Sacco, L. Zuccagnoli, S. Godin, G. Megie, J. Porteneuve, The Antarctic Ozone LIDAR system, Appl. Phys. B, B55, (1), 3-12, 1992

Tolbert M.A, Sulfate aerosols and polar stratospheric cloud formation, Science, 264, 527-528, 1994

Zhang R., P.J. Woolridge, and M.Molina, Vapor pressure measurements for the $\mathrm{H}_{2} \mathrm{SO}_{4}-\mathrm{HNO}_{3}-\mathrm{H}_{2} \mathrm{O}$ and $\mathrm{H}_{2} \mathrm{SO}_{4}-\mathrm{HCl}-\mathrm{H}_{2} \mathrm{O}$ systems: incorporation of stratospheric acids into background sulfate aerosols. J. Phys.Chem ,97, 1993(a), 8541-8548.

Zhang R., P.J. Woolridge, J.P.D. Abbatt, and M.Molina, Physical chemistry of the $\mathrm{H}_{2} \mathrm{SO}_{4} / \mathrm{H}_{2} \mathrm{O}$ binary system at low temperatures: stratospheric implications., J. Phys.Chem., 97, 1993(b), 7351-7358.

L. Stefanutti, M. Morandi, and Massimo Del Guasta, Istituto di Ricerca sulle Onde Elettromagnetiche "Nello Carrara", via Panciatichi 64, 50127 Firenze, Italy

(e-mail: lidar@iroe.iroe.fi.cnr.it; moana@iroe.iroe.fi.cnr.it)

S. Godin and C. Davide, Service d' Aeronomie - CNRS, Universitè Pierre et Marie Curie, 4 place Jussieu, 75231, Paris cedex 05, France

Received January 10, 1995 Revised May 24, 1995

Accepted June 15, 1995 